\title{
Interactions of Mesoporous Silica and Zno Nanoparticles with Escherichia Coli
}

\author{
Laxman S Meena ${ }^{1 *}$ and P D Sahare ${ }^{2 *}$ \\ ${ }^{1}$ CSIR-Institute of Genomics and Integrative Biology, India \\ ${ }^{2}$ Department of Physics and Astrophysics, University of Delhi, India
}

Submission: November 26, 2018; Published: January 25, 2019

*Corresponding author: P. D. Sahare, Department of Physics and Astrophysics, University of Delhi, Delhi, India

Laxman S Meena, CSIR-Institute of Genomics and Integrative Biology, Mall Road, Delhi, India

\begin{abstract}
Hexagonal shaped honeycomb like porous nano-structured Mesoporous Silica Nanoparticles (MSN) were synthesized by Cetyltrimethylammonium Bromide (CTAB) template base catalyzed condensation technique. TEM and XRD results in case of MSN revealed that they are $200-300$ $\mathrm{nm}$ in size having honeycomb like structure with hexagonal shaped pores all around. The porosity measurements confirmed that the MSN have pore-size of the order of $3.3 \mathrm{~nm}$ and pore-specific volume of $1.06 \mathrm{~cm}^{3} / \mathrm{g}$. Additionally, fluorescence spectrometry was performed to check the interaction of MSN and ZnO NP ( 6.0 nm) with E. coli. In case of ZnO NP for $1.0 \mathrm{mM}$ conc., the fluorescence intensity was found to decrease more rapidly than in case of the $4.0 \mathrm{mM}$ conc. with the increasing time. Proteins-NP formed a corona around the bacterial cell. Not only had the corona formed around the pathogen but also the Reactive Oxygen Species (ROS) were formed due to catalytic nature of the ZnO NP. However, of the silica nanoparticles (MSN), interaction was more with the proteins of the medium and E. coli. After entering into the cavities due to their mesoporous nature, proteins and even other small molecules soon block the cavities and stop further interactions. Studies of such kind of interactions with protein sites are rather complicated in nature but very important as these nanoparticles are being used for many applications, such as, antibacterial, labeling, drug carriers and delivery, etc.
\end{abstract}

Keywords: Nanoparticles, E. coli, ZnO, MSN, Protein corona, Interactions

Abbreviations: MSN: Mesoporous Silica Nanoparticles; ROS: Reactive Oxygen Species; CTAB: Cetyltrimethylammonium Bromide; MSN: Mesoporous Silica Nanoparticles; TEM: Transmission Electron microscopy; NP: Nanoparticle/nanoparticles; PL: photoluminescence; NaOH: sodium hydroxide; BET: Brunauer-Emmet-Teller; BJH: Barrett-Joyner-Halenda; DR: Dubinin- Radushkevich; FWHM: Full Width Half Maxima; ROS: Reactive oxygen Species; LB: Lysogeny Broth; TEOS: Tetraethyl orthosilicate

\section{Introduction}

Nanotechnology has created a plethora of diverse approaches that are being exploited for various applications in quantum electronics, sensing, catalysis, non-linear optics, biomedicines, therapeutics and many more. Nanoscale materials like Nanoparticles (NP's) have already been widely studied by the researchers throughout the world, because of their exclusive physicochemical properties. Understanding the interaction of NP's in biological system gives new dimensions to the researchers for their better and diversified use. Recently, mesoporous materials have attracted a lot of attention of researchers for their synthesis and functional mechanism [1-6]. Mesoporous materials are widely used in heterogeneous catalytic, environmental, sensory and electronic media due to their controllable and monodispersive nature of large number of accessible pores, high surface area and periodic nano-scale pore spacing forming cavities all around. Zinc oxide is another unique nanomaterial having excellent chemical and optoelectronic properties that define its significant role in areas of science and technology such as ultraviolet lasers and diodes, fluorescent labels in medicine and biology, hydrogen storage, field emitters, piezoelectric devices and photocatalysts [7-11].
The interactions of nanoparticles with biological systems are very attractive. Many studies have shown their effective role in treatment of deadly diseases like Tuberculosis and Cancer [12]. Small size and their ability to be retained in the circulation makes them very useful and revolutionary in field of medicine [9, 13-18]. Nanoparticles can be engulfed by a cell; researchers exploited this property of nanoparticles to use them in targeted drug delivery. Drug loaded nanoparticles get encapsulated by the cell and then nanoparticle degrades to release drug as per requirements. Here, we have reported results for zinc oxide prepared by chemical method and Mesoporous Silica Nanoparticles (MSN) that are prepared by Cetyltrimethylammonium bromide (CTAB) template base catalyzed condensation technique and their interaction with $E$. coli cells. The materials of different sizes, morphologies and surface activities were deliberately chosen to study their interactions with $E$. coli bacterial cells. The nanocrystalline materials were characterized by XRD and porosity measurements. Their morphology was also studied by high resolution TEM. Their interactions with the E. coli cells were studied by Photoluminescence (PL). 
It was seen that not only the particle size but the reactivity of surface as well as the porosity of the nanoparticles affect the luminescence intensity of the emission spectra. Proteinnanoparticle interactions could be analyzed by observing corona formation (as the name suggests corona is the dynamic layer of protein surrounding the NP). Here, they were observed by studying the intensity variations in the emission spectra of the fluorescence assays. These interactions display a significant role of NP in biomedicines and therapeutics.

\section{Materials}

\section{Synthesis of Mesoporous Silica Nanoparticles (MSN)}

MSN with larger pore size were synthesized by adding pore extending agent (mesitylene) to a CTAB template base catalyzed condensation reaction of Tetraethyl Orthosilicate (TEOS) [19]. Cetyl- trimethyl-ammonium-bromide (CTAB, $1.0 \mathrm{~g}, 2.7 \mathrm{mmol}$ ) was dissolved in a solution of $480 \mathrm{~mL}$ water and $3.5 \mathrm{~mL}$ of $2 \mathrm{M}$ $\mathrm{NaOH}(\mathrm{aq})$. Mesitylene $(7.0 \mathrm{~mL}, 48.8 \mathrm{mmol})$ was then added to the solution. The mixture was stirred vigorously at $80{ }^{\circ} \mathrm{C}$ for $2 \mathrm{~h}$. Tetraethyl orthosilicate $(5.0 \mathrm{~mL}, 21.9 \mathrm{mmol})$ was then added drop wise at a rate of $1 \mathrm{ml} / \mathrm{min}$ to the solution. The reaction mixture was stirred vigorously at $80{ }^{\circ} \mathrm{C}$ for another $2 \mathrm{~h}$. The resulting white precipitate was filtered, washed with abundant ethanol and dried under vacuum at $60{ }^{\circ} \mathrm{C}$ overnight. Precipitate resulted as white powder then it was refluxed with the mixture of acidic $(0.75 \mathrm{ml}$ of conc. $\mathrm{HCl})$ methanol $(100 \mathrm{ml})$ for $6 \mathrm{~h}$ at $50{ }^{\circ} \mathrm{C}$ to extract CTAB and mesitylene and to form the pores. MSN powder, thus prepared, was filtered, washed several times and dried under vaccum at $100{ }^{\circ} \mathrm{C}$ for $12 \mathrm{~h}$. The particles thus obtained were characterized by XRD, TEM, porosity measurements, etc. and were used for further studies.

\section{Synthesis of ZnO nanoparticles}

$\mathrm{ZnO}$ nanoparticles were synthesized via wet chemical method zinc acetate $\left(\mathrm{Zn}\left(\mathrm{CH}_{3} \mathrm{COO}\right)^{2} \cdot 2 \mathrm{H}_{2} \mathrm{O}\right)$, sodium hydroxide $(\mathrm{NaOH})$ as a starting material without any further purification. Stoichiometric composition was chosen for zinc acetate and sodium hydroxide. This technique is based on the hydrolysis of the precursor used to prepare $\mathrm{ZnO}$ nanoparticles. $0.1 \mathrm{M}$ solution of zinc acetate was prepared in ethanol and refluxed at $80^{\circ} \mathrm{C}$ for 6 hours which results in the formation of $\mathrm{Zn}^{2+}$ ions. Separately, $0.2 \mathrm{M}$ solution of sodium hydroxide was prepared in ethanol and added dropwise to $\mathrm{Zn}^{2+}$ ions solution under constant magnetic stirring at $40{ }^{\circ} \mathrm{C}$ and the reaction was kept for $5 \mathrm{~h}$ under continuous stirring. The obtained white precipitates were separated out using centrifugation at $6000 \mathrm{rpm}$ and washed several times with ethanol and dried at $100{ }^{\circ} \mathrm{C}$ for $12 \mathrm{~h}$. The nanoparticles thus synthesized were further characterized by XRD and TEM techniques [20].

\section{Characterization and measurements}

\section{TEM and XRD measurements}

TEM studies were performed to find out morphology and the particle size of the MSN. For that, $10 \mathrm{mg}$ of sample was mixed in $1 \mathrm{ml}$ of ethanol and sonicated for 10 mins to achieve a better dispersion of the particles [20]. A drop of the suspension was then put on carbon coated copper grid and images were taken using TECNAI TEM machine (FEI TEM model TECNAI G2 T30, U-TWIN) operating at $300 \mathrm{kV}$. X-ray diffraction spectra were recorded on PAN analytical X' Pert PRO Diffractometer using Ni-filtered CuK $\alpha 1$ $(\lambda=1.54056 \AA)$ line. The low angle XRD was taken from 1 to 100 with a scanning rate at the speed of $0.050 /$ second.

\section{Surface area/Porosity measurement of MSN}

Surface area and pore size distribution of MSN were determined using Micrometrics ASAP-2010, USA. Before the measurement, pristine MSN sample was degassed at $350{ }^{\circ} \mathrm{C}$ for 12 $\mathrm{h}$ and nitrogen adsorption-desorption isotherms were then taken. Surface area, cumulative desorption pore volume and mesopore volume were also determined using Brunauer-Emmet-Teller (BET), Barrett-Joyner-Halenda (BJH) and Dubinin- Radushkevich (DR) methods, respectively.

\section{E. coli DH $5 \alpha$ cells culture}

E. coli DH $5 \alpha$ cells were cultured as follows. Single colony from agar plate was inoculated in $25 \mathrm{ml}$ Luria Broth (LB) medium supplemented with $100 \mu \mathrm{g} / \mathrm{ml}$ ampicillin and the culture was grown at $37^{\circ} \mathrm{C}$ for overnight in incubator shaker at $200 \mathrm{rpm}$. Subculturing was done with a dilution of 1:100 in $5 \mathrm{ml} \mathrm{LB}$ medium containing $100 \mu \mathrm{g} / \mathrm{ml}$ ampicillin and various concentration of nanoparticles like $\mathrm{ZnO}$ and $\mathrm{SiO}_{2}$ for experiment to check their binding affinity with $E$. coli cells which were grown in incubator shaker at $37^{\circ} \mathrm{C}$ at $200 \mathrm{rpm}$ at various time interval $0 \mathrm{~min}, 30 \mathrm{~min}$, $60 \mathrm{~min}, 2 \mathrm{~h}, 3 \mathrm{~h}$, etc to check their binding affinity with various nanoparticles of various concentration and by simultaneously using various standard/control to check proper binding activities [21-24]. Meanwhile the samples were taken at various time intervals for analysis/observation.

\section{Preparation of different assays for fluorescence measurements}

MSN and ZnO nanoparticle binding assay was performed to directly measure the binding affinity of $E$. coli to MSN and $\mathrm{ZnO}$ nanoparticles. The assays were performed in a LB media containing (Tryptone, Yeast extract and $\mathrm{NaCl}$ ) from overnight cultured E. coli cells (DH $5 \alpha$ ). No indicator strain was used for checking MSN and ZnO nanoparticles binding activities and fluorescence from the Tryptophan present in the media was used for monitoring the binding affinity and other activities between the cells and the nanoparticles. Different concentrations of nanoparticles (MSN and ZnO) containing E. coli cells [21-24] were used. After adding the MSN and ZnO nanoparticles in E. coli cells at various incubation times, samples were collected for fluorescence measurements to check the binding activities for the MSN and ZnO nanoparticles [25].

When nanoparticles interact with $E$. coli, changes in fluorescence intensity with time indicate the binding of NP to the tryptophan amino acid. NP acts on surface of the bacteria and binds 
to the protein through tryptophan residues. Protein adsorption on NP (corona) is found to provide stability by preventing aggregation and also imparts biocompatible functionality for biological interactions. Thus, NP-protein interactions perhaps might have been well studied by studying corona formation (as the name suggests corona is the outer dynamic protein layer surrounding the NP) and also by simply monitoring the fluorescence intensity.

\section{Fluorescence measurements}

Fluorescence spectra of the E. coli assay was recorded on Varian Eclipse Fluorescence Spectrophotometer (Varian BV, now taken over by Agilent Technologies, USA) equipped with a $15 \mathrm{~W}$ flash lamp as source and a broad band PMT as a detector. The slit width and the scanning speed were kept as $5 \mathrm{~nm}$ and $5 \mathrm{~nm}$ sec $^{-1}$, respectively. A monitor PMT and the software take care of the corrections, if any, due to the nonuniform source and the detector responses. The excitation wavelength was maintained at $250 \mathrm{~nm}$ so that it excites only Tryptophan and not the ZnO NP. Equal amount $(\sim 2 \mathrm{ml})$ of the solution was taken every time in a small quartz cuvette for recording the fluorescence spectra. Each experiment was carried out at least thrice to confirm the results.

\section{Results and Discussion}

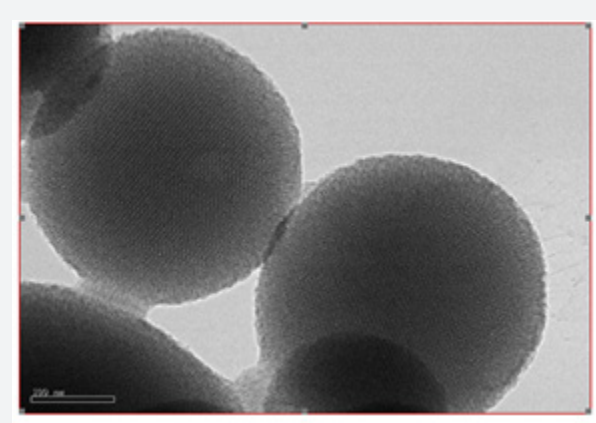

Figure 1: TEM image of the mesoporous silica nanoparticles (MSN)

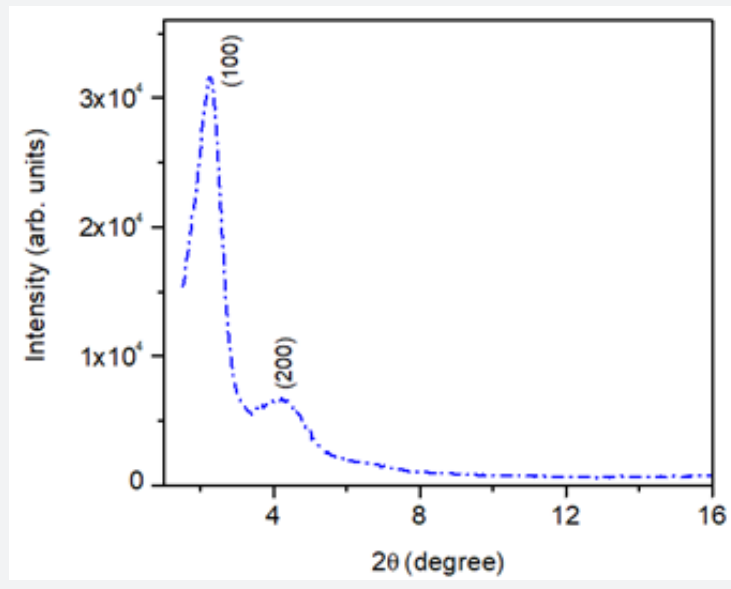

Figure 2: Low angle XRD pattern of the MSN

The morphology of prepared MSN sample was determined by TEM as shown in Figure 1. Spherical shaped MSN of $\sim 300 \mathrm{~nm}$ size having $1 \times 10^{3} \mathrm{~m}^{2} / \mathrm{g}$ surface area are seen in the figure. Honeycomb like hexagonal shaped pores were determined by TEM images that also revealed the spherical structure of MSN nanoparticles.

Table 1: Data of MSN on porosity measurements.

\begin{tabular}{|c|c|c|c|c|}
\hline Sample & $\begin{array}{c}\text { Mesopore } \\
\text { maxima }\end{array}$ & $\begin{array}{c}\text { Surface } \\
\text { area (BET) } \\
\left(\mathbf{m}^{2} / \mathbf{g}\right)\end{array}$ & $\begin{array}{c}\text { Mesopore } \\
\text { volume } \\
\text { (DR) }\left(\mathbf{c m}^{3} \mathbf{~ g ) ~}\right.\end{array}$ & $\begin{array}{c}\text { Cumulative } \\
\text { desorption } \\
\text { pure volume } \\
(\mathbf{B J H})\left(\mathbf{c m}^{3} \mathbf{g} \mathbf{)}\right.\end{array}$ \\
\hline MSN & 28 & 1026 & 0.45 & 1.06 \\
\hline
\end{tabular}

To confirm hexagonal porous structure, low angle X-ray diffraction patterns were taken. The low angle XRD pattern, XRD data and porosity measurements of material are shown in Figure 2 and Table 1 . Strong reflection peak is observed at $2 \theta$ value 2.24 (100) with d spacing at $39.5 \mathrm{~nm}$ together with one small peak at 4.26 (200) with d spacing at $20.83 \mathrm{~nm}$. The peaks are typical for hexagonal structure indicative of long-range order of such structures.

Table 2: Data for XRD and ( $\mathrm{k} \mathrm{l})$ indexing for different peaks calculated by the equation, $d=a /\left[\left(h^{2}+k^{2}+l^{2}\right)\right] 1 / 2$. The peaks at 2.24 and $4.262 \theta$ values are corresponding to (100) and (200) planes.

\begin{tabular}{|c|c|c|c|c|}
\hline $\mathbf{2 \theta}$ & $\mathbf{d}(\AA)$ ) & (h k l) & a & c \\
\hline 2.24 & 39.5 & 100 & 45.75 & 45.75 \\
\hline 4.26 & 20.83 & 200 & 46.1 & 46.69 \\
\hline
\end{tabular}

Surface area, cumulative desorption pore volume and mesopore volume were also determined using nitrogen adsorption technique and Brunauer-Emmet-Teller (BET), BarrettJoyner-Halenda (BJH) and Dubinin- Radushkevich (DR) methods, respectively. The data is as shown in Table 2 which also confirms the mesoporous nature of MSN the particles.

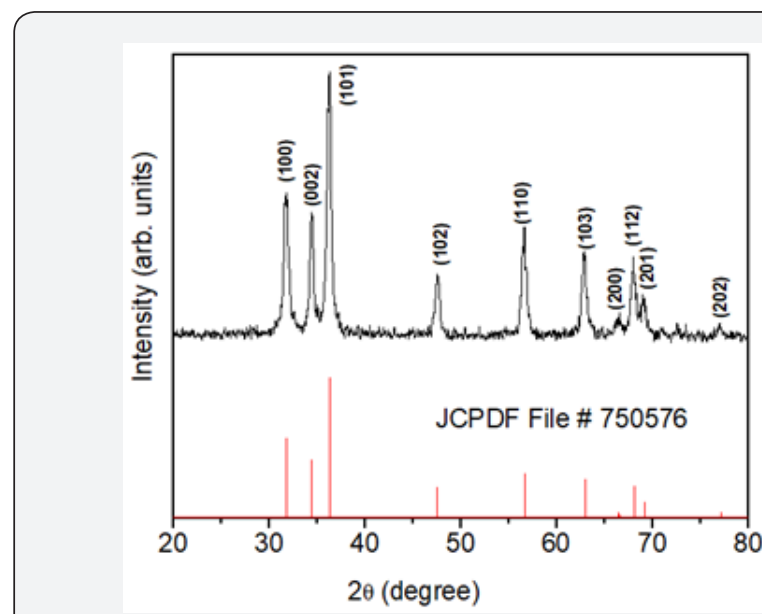

Figure 3: XRD Patterns of the $\mathrm{ZnO}$ nanoparticles

XRD pattern of $\mathrm{ZnO}$ nanoparticles is as shown in Figure 3. The average grain size of nanoparticles were estimated by using FWHM from XRD peaks line broadening. Size of nanoparticles can be estimated from a single diffraction peak using Scherrer's formula (assuming nanoparticle to be stress free), $D=0.9 \lambda / \beta \cos \theta$ where, $\mathrm{D}$ is the average grain size of crystallites, $\lambda$ is the incident wavelength, $\theta$ is the Bragg angle, $\beta$ is the diffracted FWHM (in radian) caused by crystallites. The particle size estimated from the XRD peak is found to be $\sim 6.0 \mathrm{~nm}$. The shape and size 
was also confirmed from the TEM images and spherical shaped nanoparticles of approx. same size could be seen in Figure 4.

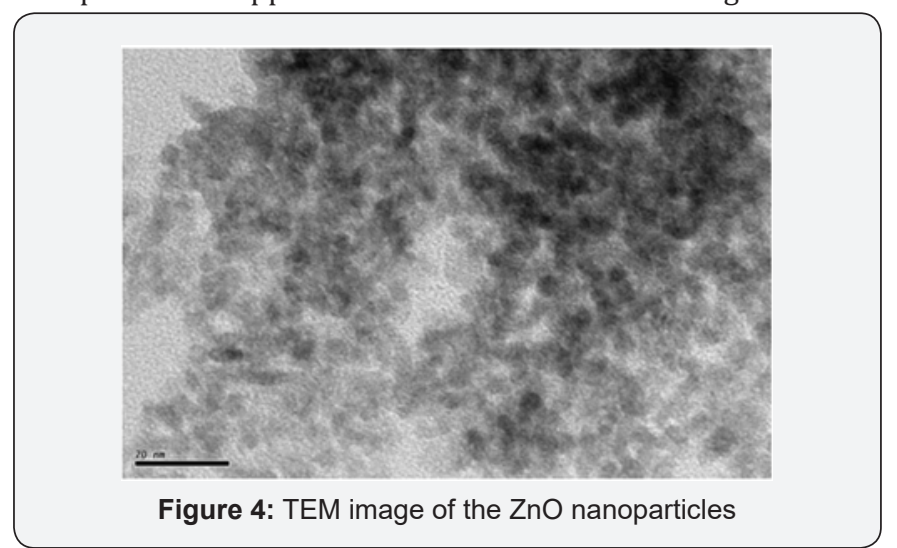

A photoluminescence (fluorescence) emission spectrum of $E$. coli in LB media (excited by $250 \mathrm{~nm}$ ) showed that with increasing time the fluorescence was decreased. The emission spectra consist of two bands, one at around $430 \mathrm{~nm}$ and another weak band at $485 \mathrm{~nm}$. It more or less resembles with the fluorescence spectra of Tryptophan (Trp). The spectra shown in Fig. 5A are for the bio-fluid (LB) and $E$. coli (negative control) and at different time periods (for time intervals 0-6 h). It could be seen from the spectra that the fluorescence was maximum initially (at $t=0$ ) and was decreased exponentially thereafter due to consumption of the LB by E. coli. Tryptophan, one of the constituents of the medium Luria Broth (LB), acts as an indicator. The decreased fluorescence intensity with time might be responsible for the decrease in Tryptophan and hence in LB.

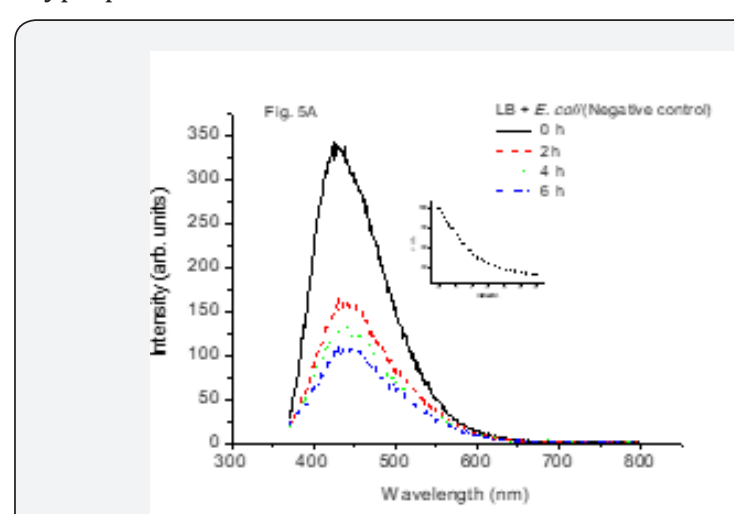

Figure 5A: Emission spectra of various assays for studing interaction of nanoparticles with $E$. coli; The fluorescence emission spectra of $E$. coli in LB media (negative control). The spectra are recorded at different time intervals to assess the consumption rate of the LB media through Trp. The decrease in the peak intensity of the emission band with time is also shown in the inset.

When we used positive control with NP along with MSN NP $1.0 \mathrm{mM}$ and $4.0 \mathrm{mM}$ concentrations at various time intervals from $0-6 \mathrm{~h}$, it did not show any change in fluorescence intensity (Figure 5A-5C). This indicates that the media and especially, the Tryptophan present in the media do not interact with the mesoporous nanoparticles. The nano size pores might be blocking the passage inside the cavity for biological macromolecules [25].
However, when the positive control with NP along with ZnO NP (1.0 mM conc.) at various time intervals from 0-6 h was used, increase in the fluorescence intensity was observed up to $4 \mathrm{~h}$. But after $6 \mathrm{~h}$, it was observed that fluorescence intensity dramatically decreases. The results are as shown in Figure 5D. The same trend observed for $4.0 \mathrm{mM}$ conc. for the same $\mathrm{ZnO} \mathrm{NP}$ and is shown in Figure 5E. This kind of behavior was very interesting but not surprising and as is expected. As the nanoparticles interact with the biomolecules in the LB media corona is formed due to proteins like Tryptophan (Trp) and there could be more energy transfer that increases the fluorescence intensity. But with time more Reactive Oxygen Species (ROS) formed due to catalytic nature of ZnO NP may be responsible for forming new complexes or even disintegrate Trp resulting in lowering the fluorescence activity (intensity) [10, 26, 27].
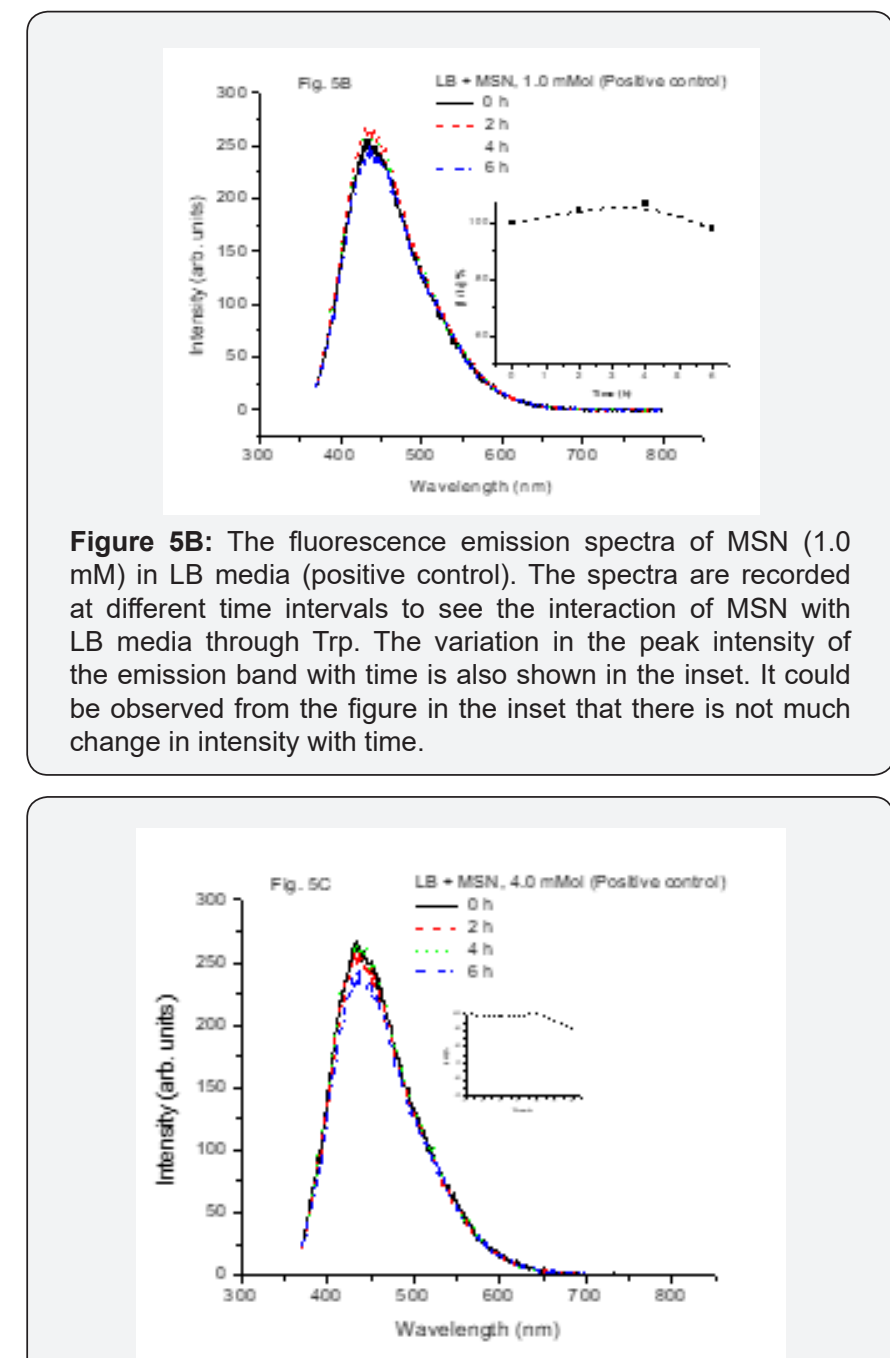

Figure 5C: The fluorescence emission spectra of MSN (4.0 $\mathrm{mM}$ ) in LB media (positive control). The spectra are recorded at different time intervals to see the interaction of MSN with LB media through Trp at higher concentration. The variation in the peak intensity of the emission band with time is also shown in the inset. It could be observed from the figure in the inset that there is not much change in intensity up to first $4 \mathrm{~h}$. However, around $10 \%$ decrease was observed after $6 \mathrm{~h}$. 


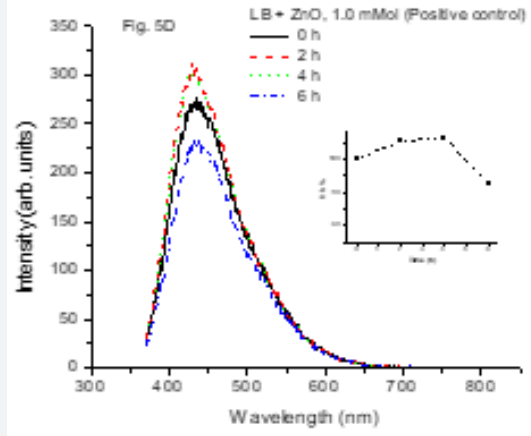

Figure 5D: The fluorescence emission spectra of $\mathrm{ZnO}$ NP (1.0 $\mathrm{mM}$ ) in LB media (positive control). The spectra are recorded at different time intervals to see the interaction of $\mathrm{ZnO}$ with LB media through Trp. The variation in the peak intensity of the emission band with time is also shown in the inset. It could be observed from the figure in the inset that there is $10-12 \%$ gradual increse in the intensity for up to first $4 \mathrm{~h}$ but then there is around $18 \%$ decrease in the intensity has been observed.

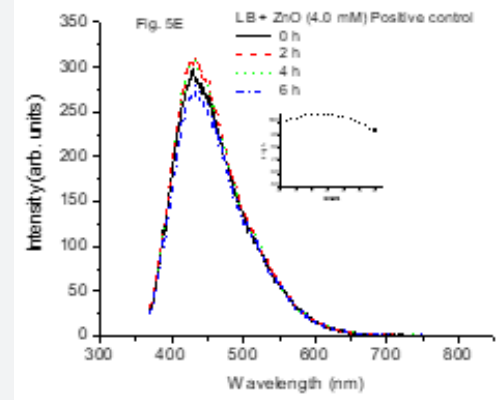

Figure 5E: The fluorescence emission spectra of ZnO NP (4.0 $\mathrm{mM}$ ) in LB media (positive control). The spectra are recorded at different time intervals to see the interaction of $\mathrm{ZnO}$ with LB media through Trp at higher concentration. The variation in the peak intensity of the emission band with time is also shown in the inset. It could be observed from the figure in the inset that there is not much change in intensity with time.

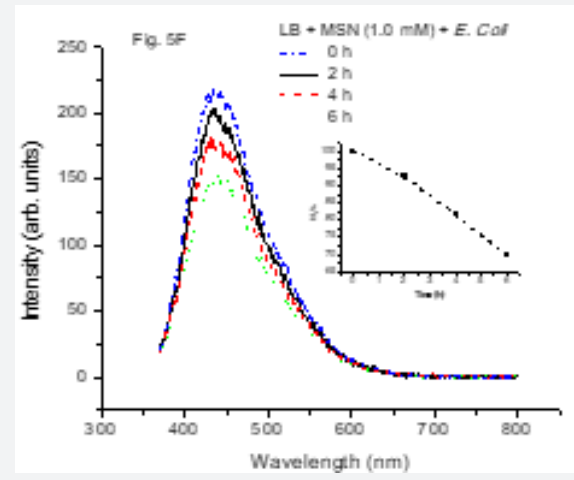

Figure 5F: The fluorescence emission spectra of MSN (1.0 mM) + E. coli in LB media. The spectra are recorded at different time intervals to see the interaction of $\mathrm{ZnO}$ with LB media through Trp. The variation in the peak intensity of the emission band with time is also shown in the inset. It could be observed from the figure in the inset that there is gradual decrease in the intensity with time. Around $30 \%$ decrease in the peak intensity was observed in $6 \mathrm{~h}$.
The interactions of MSN and ZnO NP (1.0 and $4.0 \mathrm{mM}$ conc.) with E. coli cells were then also studied by studying the fluorescence spectra with time. The emission spectrum for MSN (1.0 mM) with E. coli in LB medium is as shown in Figure $5 \mathrm{~F}$. It could be seen from the figure that there is decrease in the fluorescence intensity with time while a different behavior was observed when the MSN concentration was increased to $4.0 \mathrm{mM}$ is as shown in Figure 5G. The intensity remains almost constant up to $4 \mathrm{~h}$ but it decreases after that. This could be understood by considering the fact that the LB is consumed by the pathogens and thus the content of Trp gets reduced and subsequently its fluorescence. However, when the MSN concentration is increased, there would be more coronas formed around the nanoparticles that would decrease the rate of consumption of the media (LB) and there was no much decrease in the Trp which gets reflected in the fluorescence intensity. However, for longer periods, a decrease in the intensity could be observed due to more consumption of the media. It is also to be noted here that it is unlikely that MSNs could get internalized inside the bacterial cells due to their bigger sizes $(\sim 0.3 \mu \mathrm{m})$ without keeping the pathogen live.

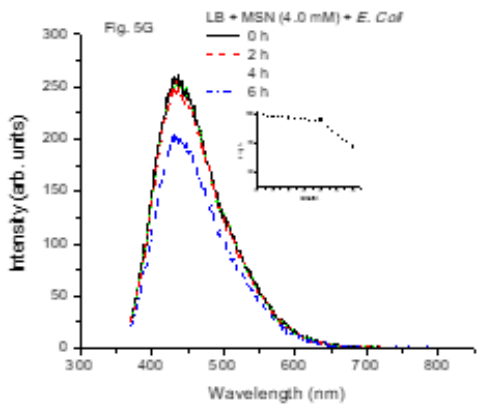

Figure 5G: The fluorescence emission spectra of MSN (4.0 mM) + E. coli in LB media. The spectra are recorded at different time intervals to see the interaction of $\mathrm{ZnO}$ with LB media through Trp. The variation in the peak intensity of the emission band with time is also shown in the inset. It could be observed from the figure in the inset that there is little decrease in the intensity for first $4 \mathrm{~h}$. However, around $25 \%$ decrease in the peak intensity was observed in $6 \mathrm{~h}$.

The emission spectrum for $\mathrm{ZnO} \mathrm{NP}(1.0 \mathrm{mM})$ with $E$. coli in $\mathrm{LB}$ medium is as shown in Figure $5 \mathrm{H}$. It could be seen from the figure that there is not much decrease in the fluorescence intensity for first $2 \mathrm{~h}$, however, as the time passes, decrease in the fluorescence intensity was observed. This may be attributed to the formation of protein corona around the nanoparticles and produce ROS. However, it would take some time and would also depend on the concentration of the NP. This might be responsible for keeping the Trp conc. the same for some time $(\sim 2 \mathrm{~h})$. However, with time there would be more generation of the ROS, which could be responsible for internalization of more $\mathrm{ZnO}$ nanoparticles and creating more toxicity making it difficult for survival of the bacteria. With time there would also be more consumption of the LB media resulting in decrease in Trp and hence the fluorescence intensity gradually. When conc. of the $\mathrm{ZnO}$ nanoparticles was increased to $4.0 \mathrm{mM}$ (as shown in Figure 5I) the initial activity was increased due to high 
conc. of $\mathrm{ZnO} \mathrm{NP}$ and as a result fluorescence intensity decreases contrary to that of the MSN for the first $2 \mathrm{~h}$ but it continued to decrease as the ROS formed in the process might be disintegrating the Trp. This could thus be attributed to more deaths of the bacteria due to generation of more ROS and less consumption of Trp but still resulting in decrease of the fluorescence intensity. However, overall decrease in rate of fluorescence intensity was observed. This would certainly depend on the optimum conditions for generation of ROS species, conc. of bacteria and conc. of NP.

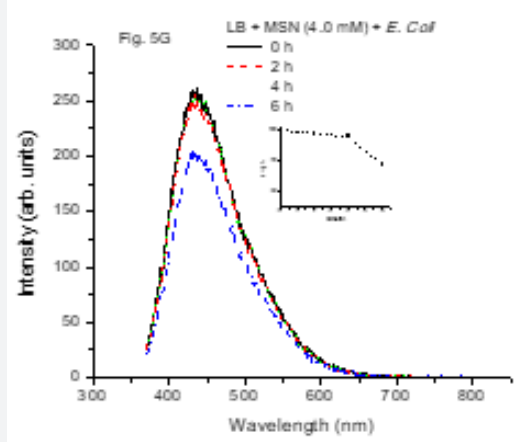

Figure $5 \mathrm{H}$ : The fluorescence emission spectra of $\mathrm{ZnO}(1.0 \mathrm{mM})$ $+E$. coli in LB media. The spectra are recorded at different time intervals to see the interaction of $\mathrm{ZnO}$ with LB media through Trp. The variation in the peak intensity of the emission band with time is also shown in the inset. It could be observed from the figure in the inset that there is no change in the intensity for first $2 \mathrm{~h}$. However, the peak intensity decreases thereafter.

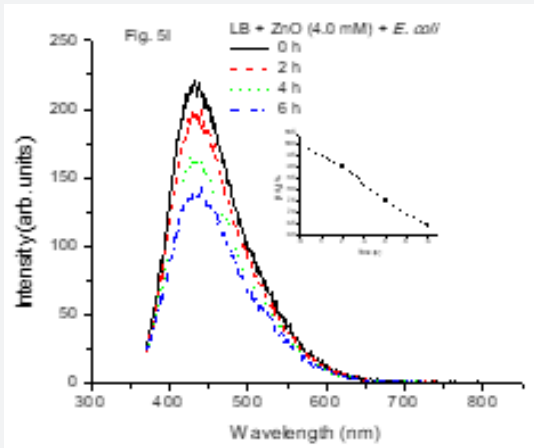

Figure 5I: The fluorescence emission spectra of $\mathrm{ZnO}(4.0 \mathrm{mM})$ $+E$. coli in LB media. The spectra are recorded at different time intervals to see the interaction of $\mathrm{ZnO}$ with LB media through Trp. The variation in the peak intensity of the emission band with time is also shown in the inset. It could be observed from the figure in the inset that there is gradual decrease in the intensity with time.

\section{Conclusion}

Nanotechnology is very fascinating in the field of biomedicines, bio-signalling, diagnostics, therapeutics, quantum electronics, sensing, catalysis, non-linear optics and many more. Different types of nanomaterials are being used in various fields. MSN and ZnO NP are of significant importance in nanotechnology. Zinc oxide were prepared by chemical method and mesoporous silica nanoparticles (spherical shape, 200-300 nm in size and 1013 $\mathrm{m} 2 / \mathrm{g}$ in surface area) were prepared by Cetyltrimethylammonium
Bromide (CTAB) template base catalyzed condensation technique. E. coli cells were treated with MSN and ZnO NP and the photoluminescence spectra were observed. Fluorescence intensity changes with increase in time indicating the binding of MSN and ZnO NP with E. coli cells. However, more detailed study is necessary to find out more such interactions. These results are very useful for the use of these nanomaterials in biological systems. The study of such interactions of bacteria with nanomaterials may become very useful in the field of biomedicines and therapeutics.

\section{Acknowledgement}

The authors acknowledge financial support from the Department of Science and Technology, Council of Scientific and Industrial Research and University of Delhi under the research project file nos. GAP0145, OLP1121 and RC/2015/9677, respectively.

\section{Conflict of Interest}

There is no conflict of interest.

\section{References}

1. Wu YS, Ma J, Hu F, Li MC (2012) Synthesis and characterization of mesoporous alumina via a reverse precipitation method. J Mater Sci Technol 28(6): 572-576.

2. Lim MH, Blanford CF, Stein A (1997) Synthesis and Characterization of a Reactive Vinyl-Functionalized MCM-41: Probing the Internal Pore Structure by a Bromination Reaction. J Am Chem Soc 119(17): 40904091.

3. Kitiwan M, Atong D (2010) Effects of porous alumina support and plating time on electroless plating of palladium membrane. Journal of Material Science\& Technology 26(12):1148-1152.

4. He QJ, Shi JL, Cui XZ, Wei CY, Zhang LX, et al. (2011) Synthesis of oxygen-deficient luminescent mesoporous silica nanoparticles for synchronous drug delivery and imaging. Chemical Communication 28: 7947-7949.

5. He QJ, Cui XZ, Cui FM, Guo LM (2009) Size-controlled synthesis of monodispersed mesoporous silica nano-spheres under a neutral condition. Microporous Mesoporous Mater 117(3): 609-616.

6. He QJ, Shi JL (2011) Mesoporous silica nanoparticle based nano drug delivery systems: synthesis, controlled drug release and delivery, pharmacokinetics and biocompatibility. Journal of Materials Chemistry 16: $5845-5855$.

7. Ramasamy M, Das M, An SSA, Yi DK (2014) Role of surface modification in zinc oxide nanoparticles and its toxicity assessment toward human dermal fibroblast cells. Int J Nanomedicine 9: 3707-3718.

8. De Louise LA (2012) Applications of nanotechnology in dermatology. J Invest Dermatol 132(3pt 2): 964-975.

9. Rasmussen JW, Martinez E, Louka P, Wingett DG (2010) Zinc oxide nanoparticles for selective destruction of tumor cells and potential for drug delivery applications. Expert Opin Drug Deliv 7(9): 1063-1077.

10. Kumar S, Sahare PD (2012) Nd-doped $\mathrm{ZnO}$ as a multifunctional nanomaterial. Journal of Rare Earths 30(8): 761-768.

11. Choi EC, Kim HJ, Boo JH, Hong B (2015) Synthesis and Application of ZnO Nanorods Using the Ultra-Thin Porous AAO Template Fabricated by New Method. J Nanosci Nanotechnol 15(11): 8395-400.

12. Meena J, Singh M, Sahare PD, Meena LS (2014) Interaction of Nanoparticles in Biological Systems and their Role in Therapeutical Treatment of Tuberculosis and Cancer. J Lum Appl 1(1): 7-22. 
13. Panchal RG (1998) Novel therapeutic strategies to selectively kill cancer cells. Biochem Pharmacol 55(3): 247-252.

14. Ferrari M (2005) Cancer nanotechnology: opportunities and challenges. Nat Rev Cancer 5(3):161-171.

15. Smith JP (2011) Nanoparticle delivery of anti-tuberculosis chemotherapy as a potential mediator against drug-resistant tuberculosis. Yale J Biol Med 84(4): 361-369.

16. Fenaroli F, Westmoreland D, Benjaminsen J, Kolstad T, Skjeldal FM, et al. (2014) Nanoparticles as drug delivery system against tuberculosis in zebrafish embryos: direct visualization and treatment. ACS Nano 8(7): 7014-7026.

17. Mathuria JP (2009) Nanoparticles in tuberculosis diagnosis, treatment and prevention: a hope for future. Digest Journal of Nanomaterials and Biostructures 4(2): 309-312.

18. Singh R, Lillard JW Jr (2009) Nanoparticle-based targeted drug delivery. Exp Mol Pathol 86(3): 215-223.

19. Zhang J, Li X, Rosenholm JM, Gu HC (2011) Synthesis and characterization of pore size-tunable magnetic mesoporous silica nanoparticles. J Colloid Interface Sci 361(1):16-24.

20. Kumari S, Sahare PD (2013) Optical studies of fluorescent mesoporous silica nanoparticles. Journal of Materials Science \& Technology 29(8):742-746.

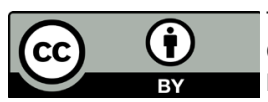

This work is licensed under Creative Commons Attribution 4.0 Licens

DOI: 10.19080/AIBM.2019.12.555840
21. Meena LS, Chopra P, Bedwal RS, Singh Y (2008) Cloning and characterization of GTP-binding proteins of Mycobacterium tuberculosis $\mathrm{H}_{37}$ Rv. Enzyme Microb Technol 42(2):138-144.

22. Meena LS, Rajni (2011) Cloning and characterization of engA, a GTPbinding protein from Mycobacterium tuberculosis H37Rv. Biologicals 39(2): 94-99.

23. Meena LS, Chopra P, Vishwakarma RA, Singh Y (2013) Biochemical characterization of an S-adenosyl-L-methionine-dependent methyltransferase (Rv0469) of Mycobacterium tuberculosis. Biol Chem 394(7): 871-877.

24. Meena LS, Rajni (2010) Survival mechanisms of pathogenic Mycobacterium tuberculosis $\mathrm{H}_{37}$ Rv. FEBS J 277(11): 2416-2427.

25. Paula AJ, Araujo RTJr, Martinez DST, Paredes-Gamero EJ, Nader HB, et al. (2013) Influence of Protein Corona on the Transport of Molecules into Cells by Mesoporous Silica Nanoparticles. ACS Appl Mater Interfaces 5(17): 8387-8393.

26. Liu Y, Gorla CR, Liang S, Emanetoglu N, Lu Y, et al. (2000) Ultraviolet detectors based on epitaxial $\mathrm{ZnO}$ films grown by MOCVD. Journal of Electronic Materials 29(1): 69-74.

27. Joshi P, Chakraborti S, Chakrabarti P, Singh SP, Ansari ZA, et al. (2012) ZnO nanoparticles as an antibacterial agent against E. coli. Sci Adv Mater 4: 173-178.

\section{Your next submission with Juniper Publishers will reach you the below assets}

- Quality Editorial service

- Swift Peer Review

- Reprints availability

- E-prints Service

- Manuscript Podcast for convenient understanding

- Global attainment for your research

- Manuscript accessibility in different formats

( Pdf, E-pub, Full Text, Audio)

- Unceasing customer service

Track the below URL for one-step submission

https://juniperpublishers.com/online-submission.php 